\title{
Plutarco Elías Calles y su política agraria
}

Laura Herrera Serna

\begin{abstract}
Cada seis años se renueva la intención de las autoridades gubernamentales de resolver el problema agrario en México; cambian nombres de funcionarios, aparecen nuevos términos en el discurso político y se elaboran vastos programas que difícilmente se cumplen.
\end{abstract}

Al hacer una revisión histórica del asunto se confirma que las propuestas fundamentales para resolver dicho problema fueron formuladas desde hace mucho tiempo y que, aunque presentan variantes, son las mismas que, entre otras, hizo Plutarco Elías Calles durante su gestión presidencial de 1924 a 1928.

El presente artículo pretende destácar la vigencia de la concepción callista del asunto y hacer un análisis de su programa para explicarnos, entre los logros y fracasos en su aplicación, por qué en la práctica sus proposiciones se mantienen vivas como un objetivo por cumplir.

El interés de esta investigación es destacar una de las facetas de Calles, hasta ahora poco reconocida: su acción sobre la solución integral del problema del campo y su importancia fundamental en la política económica.

Como introduccion al tema se analizará el desarrollo del ideario callista en la materia a partir de sus acciones concretas como militante revolucionario, como gobernador de Sonora, como secretario de Estado $\mathrm{y}$, finalmente, como presidente de la República. En este último punto se revisan, tánto en sus planteamientos como en su puesta en práctica, los diferentes aspectos que conformaron la llamada "Reforma Agraria Integral".

El ya no muy joven maestro de escuela, después de administrar algunos negocios familiares, se afilió al movimiento constitucionalista en 1913 en el estado de Sonora. Su colaboración fue valiosa no en cuanto a sus actividades militares, sino como excelente administrador. Fue destacado primero a Nogales donde empezó a controlar al grupo llamado "brokers" fronterizos que reunía a comerciantes y hacendados emprendedores, así como a intelectuales y a autoridades locales. ${ }^{1}$

Posteriormente, por sus servicios al gobierno estatal, fue nombrado comisario de Agua Prieta donde tenía autoridad para incautar bienes - ranchos, haciendas e industrias - a los "enemigos de la causa" (los que habían colaborado material o moralmente con los intereses de los privilegiados o a los que actuaban como tales al no explotar sus unidades de producción dejando sin empleo a cientos de trabajadores). Dichas incautaciones no significaron nunca la expropiación de los bienes, sino sólo su usufructo por el gobierno local. En esta medida, la frontera sonorense se constituyó en buena fuente de recursos para el sosteni-

1 Héctor Aguilar Camín, La frontera nómada: Sonora y la Revolución mexicana, México, Siglo XXI editores, 1977, p. 29. 
miento del constitucionalismo que se extendía ya a varios puntos del país. El triunfo de los constitucionalistas en la entidad le valió ser nombrado gobernador militar de Sonora en agosto de 1915. Durante su gestión como gobernador alternó en el poder con Adolfo de la Huerta, con quien siempre tuvo una estrecha relación.

Calles 'nunca se manifestó en contra de la propiedad privada; en sus decretos más radicales planteaba que sólo "por utilidad pública" pasarían a la administración gubernamental las tierras o empresas abandonadas por sus dueños, los cuales fueran considerados "reaccionarios". Como prueba de esta política se tienen el decreto de enero de 1916 y la amenaza de incautación de bienes de mayo del mismo año contra aquéllos que mantuvieran ociosas sus tierras o minas por más de ocho días consecutivos. ${ }^{2}$

El programa general de gobierno de Calles resaltaba la división de la tierra, en tanto que constituia la base de la salud nacional. ${ }^{3}$ Este programa estaba orientado a los eficientes y activos pequeños granjeros capaces de introducir en la producción nuevas técnicas, quienes además debian aprovechar los créditos que les ofreciera el banco agrícola que para ese efecto sería creado. Ejémplo de esta política fue la puesta en marcha del programa de fraccionamiento de tierras afectadas a los "enemigos de la causa", con el objetivo de crear pequeñas unidades de producción. Las tres únicas acciones de este tipo ocurrieron en Orantía y Rosales (siete ha) San Pedro, El Calvario y las Moyas (seis ha) y Santa Ana (siete ha), tierras que pasaron a manos de los antiguos peones de las respectivas haciendas. ${ }^{4}$ De igual manera, señalaba la necesidad de iniciar los trabajos de reparación de los sistemas de riego y de invertir en una amplia red de caminos en el estado.

Hacia 1916, Calles promovía la instauración de la Comisión Local Agraria en el estado, para lo cual llamó a ingenieros agrónomos experimentados, quienes, a pesar del entusiasmo inicial, se concretaron a regularizar las condiciones jurisdiccionales de pueblos y ciudades que habian ido creciendo y a establecer las zonas de dominio municipal sobre terrenos que seguían perteneciendo a empresas mineras o a haciendas colindantes. Los ingenieros de la Comisión se encargaron también de determinar las áreas susceptibles de expropiación para restituir o dotar a los pueblos, sin que esto significara que pudieran tomar decisiones, pues la determinación final era de la Comisión Nacional Agraria. A pesar de ello, Calles dictaminó la restitución de San Clemente de Terapa y Pívipa (febrero de 1916). La razón de ello es que las demandas de restitución eran muy pocas y podian ser fácilmente resueltas por la gubernatura estatal. El caso de mayor importancia en cuanto a demanda de restitución de tierras fue el de los yaquis; la respuesta de Calles, con la investidura de gobernador militar de la entidad, fue rechazarla y reiniciar la campaña represiva contra los indigenas (1915-1917), pues consideraba que la tierra debía ser poseida y usufructuada por el agricultor que la explotara racionalmente, trascendiendo la agricultura tradicional e introduciendo tecnología moderna, de acuerdo con la forma pri-

"Héctor Aguilar Camín, "The relevant tradition: Sonoran leaders in the Revolution" en Caudillo and peasant in the Mexican Revolution, Cambridge, Cambridge University Press, 1980, p. 101.

${ }^{3}$ Linda Hall, Alvaro Obregon and the Mexican Revolution 1912-1920: The origen of the institutionalization, San Antonio, Trinity University, 1976.

4 Héctor Aguilar, op. cit. p. 434. 
vada de tenencia y no como la de los indígenas de tipo cumunal y con métodos obsoletos.

La administración callista logró establecer el orden constitucional al promulgar la Ley Suprema del Estado en 1919, así como las leyes agrarias y de trabajo. De esta manera, Sonora significó para Calles un campo de experimentación en la aplicación de los preceptos vertidos en la Carta Magna de 1917 y que constituyen antecedentes incuestionables de su gestión como presidente.

En octubre de 1919 Calles fue llamado por Carranza para ocupar la cartera de Industria, Comercio y Trabajo. Durante su permanencia, hasta febrero de 1920, su actuación se circunscribió a establecer alianzas'con los líderes obrero y campesino más fuertes del momento: Luis N. Morones (Confederación Regional de Obreros Mexicanos) y Felipe Carrillo Puerto (Partido Socialista del Sureste). De hecho, siendo secretario de Industria, se mostró repetidamente irritado ante la negligencia de Carranza para realizar el programa revolucionario. El resultado de las buenas relaciones con dichos lideres se tradujo a corto plazo, en el apoyo que esas organizaciones brindaron a la candidatura de Alvaro Obregón en oposición al candidato carrancista, pues la política continuista del presidente y la de su posible sucesor era a todas luces contraria a sus intereses.

En 1920 el triunfo del movimiento de Agua Prieta, en el que Calles fue figura central, dio acceso a la presidencia interina a Ádolfo de la Huerta y Calles pasó a ocupar el puesto de Secretario de Guerra. En el periodo 1920-1924, siendo presidente constitucional Alvaro Obregón, fue nombrado Secretario de Gobernación, cargo bajo el cual dirigió sus esfuerzos a fortalecer el aparato político, a promover la organización de obreros dirigidos por Luis $\mathrm{N}$. Morones y a apoyar el programa de mano dura del gobernador de Yucatán, Felipe Carrillo Puerto. Este último planteaba y ponía en práctica la organización de obreros y campesinos en "ligas", fundaba cooperativas de producción y de consumo que permitían a estos sectores la ascensión a mejores niveles de eficiencia y además de repartir tierras entre "los que las trabajan", con lo cual Yucatán llegó a ser una de las cinco entidades de mayor redistribución de tierras en la República durante esta etapa, lanzaba ataques y controlaba con la Ley a la Iglesia; finalmente, programaba la construcción de infraestructura y daba un fuerte impulso a la educación popular.

Por este tiempo el Secretario de Gobernación fue sumamente criticado tanto por nacionales como por extranjeros, ya que se consideraba que propiciaba un cambio como el de la Unión Soviética. En relación con esto, El Omega comentaba:

...la mano de ese ministro no se concentra en la esfera de gobernación sino que extiende sus poderosos dedos a la política. Allí donde están sus hechuras predilectas, alli está el agrarismo destructor y ruinoso. Allí está también el radicalismo obrero que mata lentamente a nuestra exigua patria... ¿Qué será del país bajo la despótica mano ra. dical del supremo pontifice de nuestro comunismo azteca? ¿A dónde llegaremos bajo la férula intransigente y el espeso idealismo negro de Plutarco Elías Calles, que [...] desearía que la burguesía tuviera una sola cabeza para cortarla de un solo tajo. ${ }^{5}$

${ }^{5}$ El Omega, México, 11 de enero de 1923. 
Ciertamente, Calles seria sistemáticamente atacado por los sectores que se veían afectados por la aplicación del artículo 27 , puesto que el Secretario había hecho amplias declaraciones en las que se pronunciaba en favor de la corriente radical dentro del obregonismo, que se proponía la aplicación de leyes con un sentido racionalista.

Después de aceptar la candidatura oficial a la presidencia de la República, en septiembre de 1923, Calles inició su campaña con una plataforma politica en la que la solución al problema del campo ocupaba un lugar prioritario. Y partiendo del principio de que la ley significa "método y orden", se pronunció a favor de que las propiedades productivas no fueran afectadas. Por el contrario, aquéllas que utilizaran sistemas obsoletos serian susceptibles de ser fraccionadas paulatinamente, creándose la infraestructura crediticia y la organización cooperativa entre los campesinos. Por ello, la tierra debería distribuirse inicialmente entre los pequeños propietarios capaces de producir de acuerdo con los avances modernos, para cuyo fin se crearian los sistemas de riego y caminos necesarios.

Por otro lado, debía evitarse el excesivo fraccionamiento, ya que los efectos serian contraproducentes para la economía agrícola nacional, considerando los limitados recursos y el bajo grado de cultura del campesinado. Además, la excesiva subdivisión impedía el desarrollo capitalista del agro, al provocar una regresión en el sistema productivo y redundar en una economía de consumo. Sin embargo, a pesar de esto debía efectuarse el programa ejidal y reivindicar los derechos de los pueblos sobre sus tierras. Esta acción, señalaba, era un principio impostergable de las promesas revolucionarias. La aseveración de que la tierra debía ser para quien la trabajara, comprendía en primer término a los pequeños agricultores modernos y, en un segundo plano, a los ejidatarios y comuneros que, con los servicios que les proporcionara el gobierno, paulatinamente se irían capacitando para la producción de mercado.

Vemos, pues, que la plataforma política callista respecto a la cuestión agraria es congruente con el programa de la Revolución, y aunque contiene elementos propios de la zona norte, es, sin lugar a duda, un proyecto nacional donde también se toman en cuenta las demandas propias de otras regiones.

De acuerdo con la Constitución de 1917, Calles asumía la máxima autoridad para impulsar la creación de la pequeña propiedad, confiriéndola a los campesinos. Con ello esperaba lograr la tan deseada paz social para que el capital pudiera operar con seguridad, al tiempo que se podría establecer una relación productiva entre capital y trabajo a través de organizaciones cooperativas de producción, consumo y distribución. Asimismo, planteaba claramente que la forma de tenencia comunal o ejidal de la tierra constituiría la etapa anterior a la pequeña propiedad, la forma de tenencia ideal. Para ello, los ejidos serian divididos en parcelas y así se estimularía el trabajo del ejidatario y se preservaria al pais del acaparamiento especulador e improductivo.

Por otra parte, declaró que los campesinos que recibieran tierras estarian obligados a cultivarlas, asi como a mejorar intelectual, física y moralmente. Aquel que no cultivara la tierra que la Revolución le entregase, no la merecía y debía ser desposeído de ella.

El 2 de mayo de 1924, Calles se comprometió a cumplir y a hacer cumplir el artículo 27 y a procurar la resolución del problema agrario, planteándolo por primera vez en forma "integral", siendo la parcela 
sólo uno de los factores indispensables para el éxito; entre otros elementos complementarios tendrían que figurar el crédito agrícola, la dotación de aguas, la organización de cooperativas la construcción de caminos, etc. La "Reforma Agraria Integral" es un cuerpo de ideas bien estructurado, resultado de la experiencia, del conocimiento de la legislación en materia agraria y de los problemas y resultados de su ejecución. Así pues, Calles propuso la solución del problema agrario de tal manera que intervienen todos los elementos afectados.

El 27 de septiembre de 1924, antes de la declaración del Congreso sobre la victoria de Calles, éste salió a una gira por Europa y los Estados Unidos, siendo recibido en Alemania por el presidente Friederich Ebert. Alli entró en contacto con las organizaciones cooperativas de producción que por entonces proliferaban en aquel país, quedando impresionado por el vasto programa de reconstrucción de la posguerra. En noviembre Calles regresó a México y el 1 de diciembre recibió la banda presidencial.

El gobierno callista se preocupó por fortalecer al Estado en función de los intereses nacionales y por convertirlo en "omnipotente y dador de fuerza", de manera que la legislación favoreciera el bienestar y el progreso del pueblo. Tras la derrota del movimiento delahuertista, Plutarco Elías Calles encontró un Estado fortalecido por el apoyo de caudillos y caciques a su gobierno. Independientemente del predominio de la burguesía agraria, el gobierno comenzó a expresar, a partir de 1924, los intereses de ésta en su conjunto, los cuales pretendían una forma de control politico, es decir, un Estado capitalista estable que propiciara la extensión de la clase dominante mediante la modernización del sistema económico y del aparato político. Y como se pretendía conciliar intereses contrarios para lograr los objetivos de la nación por encima de los de clase, el gobierno concentró el poder político y canalizó sus recursos económicos de tal manera que planeó y ejecutó programas de desarrollo que respondieron a las expectativas políticoeconómicas de la burguesia.

Debido a que el capital invertido en las ramas productivas más importantes se encontraba en manos de extranjeros, el gobierno se planteó la urgencia de la capitalización y se hizo indispensable su mayor participación; esto sin dejar de reconocer la importancia de la concurrencia de los capitales extranjeros, pero normados por los principios constitucionales. De esta manera se convirtió no sólo en fuente de financiamiento, sino también en agente económico. De ahi que con la reorganización de las finanzas, la fundación de bancos, la obtención de líneas de crédito en el exterior, el gobierno tratara de demostrar su eficiencia como administrador.

Así pues, el sector industrial se convirtió en el puntal del desarrollo del país al tratar de reorganizar el mercado nacional, de modo que el crecimiento y fortalecimiento de la industria fueran resultado de la capacidad de satisfacer la demanda de bienes de consumo, sin una evidente explotación de los trabajadores y sin encarecer los productos. De esta manera el gobierno procuraba promover en los industriales un espiritu de renovación a la vez que se condenaba a quienes quisieran fundar su posición en el privilegio. ${ }^{6}$

Durante el gobierno de Calles se hicieron patentes varias transforma-

- Arnaldo Córdova, La ideología de la Revolución Mexicana, México, Editorial Era, 1974 , p. 318 . 
ciones en la estructura política e ideológica, pero no se resolvieron definitivamente las agudas contradicciones entre las fracciones de la clase dominante, principalmente en lo relacionado con la cuestión agraria. La burguesía podía alcanzar por sí sola estas reformas supraestructurales, pero no las socioeconómicas, pues para ello requería el apoyo de las masas y de los sectores medios - pequeña burguesía rural y urbana- en la tarea de reconstrucción nacional.?

Posteriormente la sumisión al Estado presentaria formas más organizadas causantes de la desvinculación de campesinos y proletarios a través de la intervención de sus eficientes líderes. De esta manera el proletariado se encontró cada vez más imposibilitado para orientar la lucha popular revolucionaria.

Por otro lado, la unión del gobierno con los diferentes sectores tenía por finalidad la ejecución de las reformas sociales y económicas que liberaran el proceso capitalista, al tiempo que la bandera nacionalista cohesionaba los intereses del país - característica propia de los países débiles - frente al imperialismo norteamericano. Con estos elementos se puede diferenciar la actuación política de Calles respecto a su antecesor en la presidencia: mientras que Obregón veía el desarrollo como justificación de su poder personal, Calles hacía de la dominación política un instrumento del desarrollo capitalista. ${ }^{8}$ Esta sería una de las características sustanciales que el nuevo Estado mexicano adquiriría.

Replanteemos brevemente las condiciones del agro hacia 1924 para, a partir de ellas, señalar las soluciones que proponía Calles durante su ejercicio. Entre los principales obstáculos para desarrollar las fuerzas productivas del campo estaban:

- La falta de capital de la mayor parte de los propietarios productivos y la nula capacidad económica de los ejidatarios y comuneros beneficiados por la reforma agraria.

- La complejidad de la formación social a lo largo del país.

- La existencia de gran cantidad de campesinos sin tierra y sin la posibilidad de ser absorbidos por la industria.

- La depauperación de gran parte del campesinado, lo que provocaba una tendencia a la baja en el mercado interno.

- La reducción de la producción agrícola que hacía necesaria la importación de cereales.

- La carencia de una eficiente infraestructura indispensable para la distribución.

- La mayor parte de las tierras-laborales eran propiedad privada pero estaban improductivas o se mantenían en una economía natural.

- No se contaba con tecnología moderna a excepción de algunos centros agrícolas del norte de la República.

- La presión constante de los norteamericanos que, junto con los latifundistas mexicanos, se oponían a la aplicación de la ley agraria, exigiendo además la indemnización por concepto de afectaciones.

- A veces, las afectaciones a los pequeños propietarios provocaron que se lanzaran abiertamente contra los agraristas.

7 Roger Bartra, Campesinado y poder político en México, México, Editorial Era, 1982, p. 20-23.

${ }^{8}$ Arnaldo Córdova, op. cit., p. 314. 
- Las tierras dotadas que habian beneficiado a un reducido número de campesinos, en general no eran aptas para la agricultura. "

- La legislación agraria, por inmediatista, resultaba complicada en su aplicación y en ocasiones, contradictoria.

- El Comité Administrativo, responsable de ejercer la autoridad en el ejido, lejos de responder a los intereses colectivos, utilizaba el puesto para fines personalistas.

- Los créditos beneficiaban principalmente a los "herederos de la Revolución".

Ante este panorama, el gobierno callista expidió una serie de leyes tendientes a resolver el problema. De este modo se continuaba con la tradición liberal en la que la legislación constituye el elemento definitivo para la consecución de los objetivos. En este caso la ley se convierte en un instrumento y por lo tanto es maleable, pues se adapta a la correlación de fuerzas imperantes.

La base de la legislación es la propiedad privada, aun cuando coexista con otras formas de tenencia, ya que es "... el factor esencial de la prosperidad de esa rama de la riqueza pública". ${ }^{9}$ Es así como cobra sentido la "utilidad pública" que para el gobierno significaba la constitución de la pequeña propiedad a través del fraccionamiento de latifundios y el cambio que debían sufrir los ejidos y comunidades agrarias.

Para Calles la forma de tenencia ideal era la pequeña propiedad, pues explotándose racional y científicamente no sólo satisfaría la demanda interna, sino que además produciria un excedente exportable cuyo producto se reinvertiría o se transferiría a otras ramas de la producción como la industria; asimismo se mejoraría el nivel de vida del agricultor, ampliándose el mercado interno y, finalmente, al engrosarse la capa media rural, se amortiguarian las contradicciones entre los que tuvieran y los que no tuvieran tierras, evitándose de ese modo las manifestaciones violentas que representaban un freno al desarrollo.

Al mismo tiempo planteaba que la solución al problema agrario debía ser prioritariamente de orden técnico ya que, asi, traería como consecuencia las soluciones políticas. Por eso él y sus colaboradores, entre ellos y en primer término Luis L. León, secretario de Agricultura y Fomento, analizaron el conjunto de aspectos que debian abordarse inicialmente desde el punto de vista legal: 1. Financiamiento; 2. Infraestructura; 3. Tecnología; 4. Colonización; 5. Educación agrícola; 6. Organización agrícola y 7., Reparto Agrario.

\section{Hacia la reforma agraria integral}

\section{Financiamiento}

Entre las expectativas de Calles, desde que era gobernador de Sonora, estuvo la de crear una institución de crédito agrícola que refaccionara a los campesinos y que fomentara el ahorro, lo cual fue factible cuando, ya en la presidencia, en 1925, creó el Banco de México, recibiendo Manuel Gómez Morín el encargo de realizar el estudio para elaborar la ley que creara el Banco Nacional de Crédito Agrícola.

El aspecto central de la Ley de Crédito Agrícola que se publicó el 10

9 Plutarco Elías Calles, Informe presidencial, septiembre de 1925. 
de febrero de 1926, era que el Estado se daba a la tarea, a través del Banco Nacional de Crédito Agricola, de organizar a la sociedad rural en forma de cooperativa para recibir financiamiento, al tiempo que se convertía en el principal inversionista del proyecto. Esta Ley, aunque fue modificada después, mantuvo las bases fundamentales.

Los objetivos del Banco eran:

a) Fomentar, reglamentar y vigilar la constitución y el funcionamiento de las sociedades de crédito agrícola.

b) Hacer préstamos de avio, refaccionarios e inmobiliarios para fines agrícolas, para la construcción de obras permanentes destinadas al mejoramiento de los terrenos y para la adquisición, fraccionamiento y colonización de tierras.

c) Emitir obligaciones, bonos agricolas o de caja y bonos hipotecarios, y autorizar y garantizar las emisiones de bonos de caja o agricolas que hicieran las sociedades regionales de crédito.

d) Vigilar y garantizàr las inscripciones en el Regıstro Público de Crédito Agrícola.

e) Practicar operaciones bancarias y comerciales y celebrar contratos y ejecutar los actos conducentes a su instituto. ${ }^{10}$

El Banco fue concebido como el centro del sistema de crédito agrícola formado por sociedades regionales de crédito, sociedades locales, uniones de sociedades, bancos agrícolas regionales, refaccionarios y almacenes nacionales de depósito.

También reglamentaba ampliamente las operaciones de las instituciones de crédito agricola para el beneficio de sus socios, así como las compras y ventas en común, la industrialización, el almacenamiento y el transporte de los productos, entre otros aspectos.

Desde el punto de vista organizativo, se planeó la sociedad regional de crédito para medianos agricultores, pero también para individuos ligados a la producción agrícola (transportes, irrigación, comercialización, etc.). Estas sociedades tendrían como mínimo diez socios y tendrian que aportar capital; así, el Banco captaría un determinado ahorro al tiempo que representaría una cierta garantía para la institución. Con estas sociedades se pretendía dar comienzo a la dèscentralización del crédito, ya que las sociedades regionales tenían capacidad para emitir bonos agrícolas de caja o hipotecarios, pero éstos primero debían ser autorizados por el Banco de México y en segunda instancia por el Banco Nacional de Crédito Agrícola.

Por otra parte, la ley preveía la creación de las sociedades locales de crédito que agruparían a pequeños productores, aparceros, arrendatarios y comuneros. De esta manera, superarian con su organización cooperativa la exigencia de tener un capital inicial que garantizara los créditos. La función principal de las sociedades locales de crédito era obtener, como cooperativa, financiamiento del Banco para a su vez, concederlo a sus miembros. Sin embargo, la debilidad, pequeñez y aislamiento de las sociedades locales hizo necesario que la ley estableciera una forma superior de organización: la unión de sociedades locales de crédito que facilitara las operaciones y coordinara el movimiento eco-

10 Véase en Moisés Ochoa Campos, Câlles el estadista, México, Editorial Trillas p. 138. 
nómico y productivo para lo cual éstas agruparían un mínimo de diez sociedades locales. En la práctica, el Banco Nacional de Crédito Agricola -con Elias S. A. de Lima como director y como subdirector Marte R. Gómez- se preocupó desde el principio por trabajar con propietarios particulares, con recomendados y con políticos, y muy poco por la organización de su potencial clientela, desvirtuando con ello el principio cooperativo del sistema.

En cuanto a las sociedades regionales de crédito, la acción del Banco fue pobre, pues sólo se fundó una organización de este tipo, lo que refleja también el escaso interés de los medianos capitalistas por la organización cooperativa; por lo que se refiere a las sociedades locales de crédito, en 1927 existían 378 que agrupaban 17000 miembros, es decir, $13 \%$ de la población rural del país. En estas condiciones de poca o nula operatividad para los medianos y pequeños productores, el Banco continuó funcionando fuera de sus objetivos iniciales, lo cual lo llevó, dos años después, a presentar pérdidas muy altas.

La creación en junio de 1926 del Banco Cooperativo Agrícola fúe otro intento para financiar el campo; sin embargo, al quedar su administración en manos de la CROM, bajo la dirección de Ricardo Trevino y Vicente Lombardo Toledano, su capital (100 000 pesos exhibidos y 200000 por aportar el gobierno federal) fue utilizado para el patrocinio de campañas politicas, asambleas y convenciones de esa organización. Por esto, después de un año y medio de operar, el Banco desapareció.

El Banco Ejidal fue la tercera institución de crédito agrícola creada por decreto del 16 de marzo de 1926, dirigida particularmente a los ejidatarios, sector que no había sido considerado explícitamente por la Ley de Crédito Agrícola. Los autores del proyecto, Gonzalo Robles y Jesús Silva Herzog, se propusieron que los bancos ejidales fueran fundados por la Secretaría de Agricultura y Fomento, por conducto de su Dirección de Escuelas Centrales Agrícolas en los estados, con el fin de que facilitaran el crédito "para fomento de sus explotaciones y mejoramiento de sus hogares a los poseedores de parcelas ejidales que se organizaran cooperativamente". ${ }^{11}$

En ese periodo se crearon nueve bancos ejidales en algunas entidades de la República y se constituyeron 262 cooperativas, número que superó a aquéllos afiliados a las sociedades locales de crédito. Sin embargo, en su operación, estos bancos adolecieron de serias irregularidades, pues una vez más el crédito a favor de individuos prevaleció sobre el colectivo, alcanzando este último sólo el $15 \%$ de los créditos otorgados hasta 1928.

Por otra parte, la corrupción y las pérdidas sufridas por los bancos ejidales provocaron la centralización de las operaciones crediticias agricolas en una sola institución; así, con la reforma a la Ley del Crédito Agrícola en 1931 se decretó la liquidación de los bancos y de las cooperativas ejidales que dependerían de ellos.

Dada la estructura agraria, los intentos del gobierno callista por participar en el financiamiento del desarrollo del campo hicieron que su acción fuera confundida con un subsidio y fomentara el beneficio de algunos sectores o se viera influida por criterios políticos que acabaron nulificando los objetivos originales de estas instituciones. 


\section{INFRAESTRUCTURA}

Riego. Otro problema considerado de orden técnico era la apertura de nuevas tierras al cultivo, cuya solución se planteó mediante la creación de sistemas de riego y cuyo instrumento inicial fue la Ley de Irrigación de Aguas Federales del 4 de enero de 1926. Esta iniciativa es la que probablemente refleja con más claridad el proyecto del país que Calles y sus técnicos, especialmente Alberto J. Pani, secretario de Hacienda, se planteaban. Por esta ley se creaba el organismo encargado de realizarla: la Comisión Nacional de Irrigación, que debia efectuar los estudios correspondientes y hacerse cargo de los proyectos que ya existían. La Comisión quedó integrada exclusivamente por representantes de la Secretaría de Agricultura y, por lo tanto, dicha dependencia fue la responsable de su desempeño.

En la exposición de motivos de la Ley se destacaban los objetivos fundamentales: ampliación del área de cultivo, aseguramiento de las cosechas y mejor producción agrícola; creación de la pequeña propiedad mediante el fraccionamiento de tierras que se irrigaran y, finalmente, la liberación económica de una considerable fuerza de trabajo campesina al fijarla a la tierra como pequeños propietarios, y declarar de "utilidad pública" la irrigación de las propiedades agrícolas privadas.

La concepción del "farmer" mexicano, consideraba Calles, tomaría forma al proveer de lotes familiares beneficiados por el riego, no a los ejidatarios ni a los grandes propietarios, sino al campesino medio que ocupaba un grado social y cultural entre los dos extremos.

Prevalecía entonces la idea de que los beneficiarios de las obras de riego podían pagar gran parte de su costo a corto plazo y que, por lo tanto, sería suficiente crear un fondo revolvente para ir realizando las obras. Los planes del gobierno consideraban la irrigación de medio millón de hectáreas en el cuatrienio, duplicando todo lo realizado en este aspecto hasta entonces; por eso cada año se incrementó el presupuesto respectivo: $1.6 \%$ en $1926,4.6$ en 1927 y 6.9 en $1928 .{ }^{12}$ La ley preveía también la construcción de sistemas de riego por la iniciativa privada, asi como los mecanismos de control de éstos por la Comisión. Los proyectos que el gobierno puso en marcha fueron totalmente financiados con fondos federales que ascendian a 15 millones de pesos en 1927.

La corrupción y el hecho de abordar el problema con criterio politico más que técnico, llevaron a un resultado lejos de las expectativas iniciales. Sin embargo, para 1927 se habian concluido los trabajos de tres presas en Tamaulipas y Michoacán, mientras se realizaban los estudios para las obras de cuatro más en el norte y se tenían en explotación dos zonas de riego en el centro del país. Por otra parte, en 1928 se continuaron las obras que regarian $118000 \mathrm{ha}$, a pesar de que no fueron concluidas en este periodo. Estas obras representaron el inicio formal de la política hidráulica que ha integrado posteriormente al cultivo gran número de hectáreas de tierras antes áridas.

El resultado de la empresa del riego redundó, no en la creación de pequeñas unidades de producción tipo "farmer", sino en verdaderas empresas agrícolas que emplearon gran cantidad de fuerza de trabajo, pues en la extensión de la llamada "pequeña propiedad", que en tiempos de Calles era de 150 ha, era sumamente difícil que un agricultor y su

12 Enrique Krauze, et al. Historia de la Revolución Mexicana, 1924-1928. La reconstrucción económica, México, El Colegio de México, 1977, p. 134. 
familia fueran la única fuerza de trabajo para explotarlas en su totalidad.

Por otra parte, es obvio que esta iniciativa tendiente a crear la pequeña propiedad debia orientarse a las zonas de mayor disponibilidad de tierras y recursos hidráulicos; es decir, donde hubiera menor presión de demanda de ejidos y donde, por su situación geográfica, fuera fácil la distribución de la producción, principalmente para exportarla a los Estados Unidos.

Caminos y ferrocarriles. La urgencia de ser autosuficiente en la producción de alimentos básicos tendría que ir aparejada con buenas vías de comunicación en el país. El 30 de marzo de 1925 Calles creó la Comisión Nacional de Caminos, dependiente de la Secretaría de Hacienda, que se dedicaría a elaborar el proyecto de caminos; y que se organizó de acuerdo con la Ley de Caminos y Puentes de abril de 1926. El erario federal financió por completo estas obras con fondos obtenidos en su mayoría del impuesto a la gasolina y al tabaco, por lo que no fue necesario recurrir al crédito externo.

Las rutas más importantes que se hicieron en este periodo fueron las carreteras de Puebla, Pachuca y Acapulco; se siguió también la construcción de la de Laredo, de tal manera que en 1927 sumaban dos mil kilométros terminados.

La política de construcción de caminos traduce la visión de los técnicos del régimen, política que, a la vez que centralizaba más el poder políticoeconómico en la sede de los poderes federales, tendía a fortalecer el comercio internacional, ligando a la República con los puntos de distribución más importantes del exterior. Y lo mismo se puede decir de los ferrocarriles, cuya ampliación correspondió al fortalecimiento de los centros agrícolas del norte (Sonora, Sinaloa y Nayarit) al construirse el tramo Tepic-La Quemada (dos mil kilómetros) que unió los Ferrocarriles Nacionales de México con el Ferrocarril Sudpacífico.

Tecnología. De acuerdo con la eficacia de los tres aspectos que hemos mencionado, el avance de la tecnología en el campo fue correlativa. De hecho, los principales beneficiarios, tanto de los créditos de los bancos recién creados como de la apertura de nuevos sistemas de riego, fueron un número reducido. Entre ellos se encontraban allegados al gobierno y nuevos lideres locales egresados de las filas revolucionarias, quienes, en este periodo pudieron comprar y poner a funcionar maquinaria importada que elevó notablemente la producción en sus propiedades. Aunado a esto, introdujeron semillas mejoradas, fertilizantes, rotación de cultivos, etc., destinando la producción exclusivamente al mercado externo, con lo cual quedaba claramente configurada la geografía de la nueva política económica callista, es decir, el desarrollo del norte y del noroeste del pais.

\section{COLONIZACION}

Esta se planeó con carácter técnịco y, para que este objetivo se alcanzara, debian crearse las condiciones óptimas, ya que, se argumentaba, por ello habian fracasado los intentos oficiales anteriores. Para crear esas condiciones se establecieron prioritariamente sistemas de riego y redes de caminos; la ley inmediata fue la Ley de Colonización del 5 de abril de 1926 que imprimía un nuevo ritmo a la formación de asentamientos, tanto de nacionales como de extranjeros, declarando de utilidad pública la colonización de propiedades agrícolas privadas que se 
encontrasen en las condiciones determinadas por la Ley.

Estas tierras podían obtenerse de: 1. Los terrenos nacionales y los que se adquirieran con la Ley de Irrigación; 2. Los que adquiriera el Banco Nacional de Crédito Agrícola, y 3., Los terrenos de propiedad particular en los términos de esa Ley. De hecho, con este último punto se iniciaba el fraccionamiento de la gran propiedad productiva tendiente a crear e impulsar a la pequeña propiedad, prohibiendo la venta dentro de los perímetros de los distritos de riego. La superficie máxima que el propietario podía retener no debía ser superior a $100 \mathrm{ha}$; sin embargo, si la propiedad original las excedía, tenia derecho a obtener otras tantas al mismo valor de cuando no estaban irrigadas; el resto sería expropiado por el gobierno federal al valor comercial antiguo. El costo de la expropiación sería cubierto por los futuros colonos, quienes podrían obtener de ocho a 100 ha a un plazo de 25 años y con un interés anual del $4 \%$. Se preveía el mejor acondicionamiento de esos terrenos a fin de que fueran de alta productividad, estableciendo las dimensiones convenientes de acuerdo con la calidad de los terrenos: de tierras de riego, la fracción sería de cinco a 150 ha; de temporal de primera, de 15 a 250 ; de temporal de segunda, de 20 a 200 ha, y cerriles y de agostadero de 500 a 5000 ha.

Se daría preferencia a los arrendatarios del predio y a los vecinos de la localidad; no tanto a los extranjeros, quienes debian regirse por lo establecido en el artículo 27 constitucional.

Aunque la colonización en estas nuevas tierras productivas no fue inmediata, desde 1926-1927 empezaron a formarse colonias, especialmente donde no habia gran densidad de población; en este proceso se llegó en los años siguientes a 200 colonias con dos millones de hectáreas y aproximadamente 13 mil colonos. Mientras, en las zonas donde existían centros de población, los beneficiarios fuerón los propios vecinos. Por otra parte, la creciente emigración de campesinos a los Estados Unidos, que requería mano de obra barata y abundante en sus plantaciones del sur, fue otro factor que, aunado a la baja capacidad de compra de la mayoría campesina, impidió que este sector fuera el que realmente se beneficiera.

\section{EDUCACION}

La educación siempre ocupó un lugar importante dentro de las preocupaciones de Calles. De esta manera, siendo su secretario José Manuel Puig Casauranc y subsecretario Moisés Sáenz, impulsó en forma determinante la educación rural a la cual se confirieron atribuciones más amplias que en el cuatrienio anterior, pues se consideró como el. agente socializador de la comunidad. Calles y sus técnicos veian la educación como un instrumento no sólo para “...aglutinar al campesino en torno del Estado, sino también orientar su trabajo desde el punto de vista técnico y educarlo en la conciencia de pertenecer a un concierto nacional". ${ }^{13}$

Dentro, pues, de la reforma agraria integral, la educación tenía un papel determinante, pues era el punto de contacto entre la comunidad campesina y el gobierno y era el medio a través del cual se lograría una efectiva retroalimentación entre ambas entidades; por ello Calles decía: “... que donde se dieran tierras, se pusiera una escuela y que las Se-

"3 Arnaldo Córdova, op. cit., p. 344. 
cretarías de Educación y de Agricultura debian marchar como hermanas". 14

El primer elemento debía ser la escuela rural que estaría - según la concepción de Saénz, su promotor- “... en el centro de la comunidad, el sustituto social de la Iglesia. Los niños aprenderian a trabajar y a vivir, y en segundo término a leer y escribir. Los padres de familia gobernarían la escuela por medio de comités. La escuela integraría a México". ${ }^{15}$ Se dio un gran impulso a la escuela rural indígena y se creó "La Casa del Pueblo", convirtiendo al maestro en orientador y promotor de la comunidad, al tiempo que continuaron operando seis Misiones Culturales (institución creada por Vasconcelos) que recorrieron gran parte de los estados de la República. De las escuelas rurales según el plan de educación se seleccionaría a los mejores estudiantes de cada comunidad, los cuales serian enviados a las Escuelas Centrales Agrícolas.

También se crearon las Escuelas Centrales Agricolas, pretendiendo adecuarlas a las características de cada región, en las que se prepararía a los alumnos en forma práctica, con los mejores métodos, para incrementar la prodúcción agrícola de su zona, con lo que a su vez se ampliaria la capacidad de consumo. Se pretendía que los estudiantes, al término de los estudios, se reintegraran a sus comunidades y pusieran en práctica lo aprendido; para eso se crearon dos escuelas con doscientos alumnos y con maestros egresados de la Escuela Superior de Chapingo.

Paralelamente se crearon "La Casa del Estudiante Indígena" y los "Internados Indigenas Regionales" cuyo objetivo era el mismo de las Centrales Agrícolas, sólo que recibían exclusivamente indígenas.

Fueron pocos los logros de los objetivos que programó la administración callista, dado que su planteamiento no partió de los requerimientos y necesidades objetivas de cada comunidad y en cambio se trató de que la educación fuera un agente directo de cambio; por otra parte, la separación de los estudiantes de sus comunidades originales propició que, al tener nuevas alternativas económicas y sociales, no se reintegraran a sus pueblos y, por lo tanto, no revirtieran ahi sus conocimientos.

Otro aspecto que coadyuvó al fracaso del plan educativo fue la penuria del régimen callista, lo cual determinó mayor austeridad en el ejercicio de esta Secretaría, a diferencia de las erogaciones de este ramo, que en 1923 ascendieron al $15 \%$ del presupuesto total de la Federación, y de 1925 a 1927 el promedio fue de sólo 7.06 por ciento. ${ }^{16}$

Los pocos logros demostraron que la educación no constituía el factor determinante de la transformación, pues para que ésta se realizara, se debia modificar la condición estructural del campo mexicano.

\section{ORGANIZACION}

Dado que la lucha del gobierno callista por el control de toda organización popular fue una constante durante el cuatrienio, podemos distinguir, desde su principio, tres niveles en el orden organizativo que proponia a los campesinos: 1 . La relación entre el gobierno central y las grandes organizaciones; 2 : La relación entre los poderes estatales y las

14 Moisés Ochoa, op. cit. p. 76.

is Enrique Krauze, op. cit., p. 275.

16 Ibidem, p. 309. 
organizaciones locales (que no siempre es concomitante con el primer nivel) y 3. La organización en el interior de la comunidad campesina.

En cuanto al primer nivel, a pesar de que había contado con el apoyo del Partido Nacional Agrarista a su candidatura, desde el principio de su gestión, Calles fortaleció decididamente a la CROM, que contaría con los mayores recursos económicos y políticos. El objetivo era destruir o disminuir la influencia de los caudillos y caciques locales, quienes desde años atrás habían estado organizando a la base rural para mantener una cierta independencia del centro y favorecer sus intereses personales. La CROM y el Partido Laborista tenían experiencia organizativa congruente con la política oficial, mientras el Agrarista, si bien contaba con la mayor representatividad del sector campesino, no había organizado eficazmente sus bases y por otra parte, constituía un elemento de presión para el gobierno en cuanto a la redistribución de tierras. La injerencia de los laboristas en la organización campesina se reforzó con el nombramiento de Luis L. León como secretario de Agricultura, quien tenía una larga trayectoria como militante callista y una muy estrecha relación con Morones.

Desde los inicios de esta nueva administración, la CROM trataría de extender su jurisdicción no sólo afiliando a obreros y trabajadores urbanos, sino también a los del sector rural. Fue entonces cuando surgieron fuertes discrepancias con el PNA (Partido Nacional Agrarista) que se sintió invadido en su área de acción. Estas discrepancias se manifestaron desde la Cámara de Diputados hasta llegar a enfrentamientos violentos entre los miembros de ambas organizaciones.

Morones cuestionaba la acción proselitista del PNA, llamándolos "manipuladores del campesinado", pues este partido sólo se preocupaba -decía- por fomentar la presión por el reparto agrario, mientras que ellos, los laboristas, se planteaban el problema desde el punto de vista social y económico; y aunque no estaban en contra de la entrega de ejidos, sí consideraban que la tierra debía ser entregada a quienes realmente pudieran explotarla.

Los agraristas por su lado, aparte de exhibir la corrupción de los lideres cromistas, reclamaban para sí el reclutamiento de los ejidatarios en tanto que los laboristas - proponian - se encargaran de los asalariados del campo.

No obstante, los laboristas ganaron posiciones actuando como consejeros de los campesinos que solicitaban la restitución de sus tierras o como intermediarios entre las organizaciones campesinas y la Secretaría de Agricultura y Fomento y la Comisión Nacional Agraria; además el Comité Central de la CROM creó en su seno una rama agraria a la que se pretendía dar mayor impulso. Se decía que la organización contaba en 1926 con un millón de afiliados campesinos en toda la República (cuando de hecho sólo cotizaban trece mil).

Entre otras organizaciones que también entraron en pugna con la CROM y que se declararon abiertamente contra Calles, estuvo la Confederación General de Trabajadores, de corte anarquista; ésta alentaba a los campesinos a la ocupación directa de tierras y a que se constituyeran en "comunidades libres" que, unidas, se defenderían del ejército y de los terratenientes, y decía contar con una membresía de 35 mil campesinos.

Por su parte, las Ligas Campesinas que se habían formado en algunos estados y que de alguna manera habian servido de apoyo a los líderes locales, hacian manifiesta su combatividad al constituirse, con 158 
delegados que representaban a 300 mil campesinos de 16 estados, en la Liga Nacional Campesina, bajo la dirección del Partido Comunista Mexicano (noviembre de 1926). La declaración de principios de la Liga revela un gran avance en el planteamiento ideológico de sus dirigentes: respeto irrestricto a los artículos 27 y 123; perfeccionamiento del sistema ejidal y de su organización cooperativa; socialización de la tierra y de otros medios de producción y fomentar la relación con organizaciones campesinas internacionales, fortalecer la relación con el proletariado para luchar contra el sistema capitalista y apoyar a los gobiernos que lucharan contra la influencia clerical y explotación económica. ${ }^{17}$

El segundo nivel (la relación que se establece entre los gobiernos estatales y las organizaciones campesinas locales) comprende los casos en los que los gobernadores organizaron con sus propios recursos a los campesinos, como una forma de fortalecimiento frente a una CROM todopoderosa. Los casos más representativos fueron los de Tamaulipas y Veracruz.

Emilio Portes Gil, gobernador de Tamaulipas, organizó a los campesinos en una Liga de Comunidades Agrarias y Sindicatos Campesinos. Esta iniciativa, más la dotación provisional de tierras y la promoción de la escuela rural, le permitieron obtener fuerza para fundar el Partido Socialista Fronterizo, que resultó ser una poderosa red de apoyo para su gobiernó. En estas organizaciones la CROM no tuvo cabida y no pudo ejercer ningún control.

El otro caso relevante fue la Liga de Comunidades Agrarias de Veracruz, patrocinada por Adalberto Tejeda, gobernador del estado durante la administración de Obregón. Tejeda, contraviniendo las órdenes del entonces presidente, consintió que los campesinos se armaran para defender sus tierras de los terratenientes y de sus guardias blancas. La dirección de esta Liga estuvo a cargo de Ursulo Galván y del Partido Comunista Mexicano, mismos que en 1926 convocaron al Congreso Nacional de donde surgiría la Liga Nacional Campesina.

Si Adalberto Tejeda contó con el apoyo de la CROM, aun cuando ésta no había tenido mucho éxito en el reclutamiento de campesinos veracruzanos, no ocurrió lo mismo con su sucesor en la gubernatura, Heriberto Jara. La posición de Jara propició innumerables ataques del Comité Central y de los cromistas de la entidad, quienes colaboraron para minar la base de apoyo del gobernador dentro del mismo Congreso local.

Mientras, en otras entidades, la CROM tuvo mayores logros y pudo imponer gobernadores o destituir a aquéllos que se manifestaran en contra de esa organización; esto sucedió en Jalisco, Puebla, Zacatecas, Coahuila, Chiapas, Estado de México y Michoacán.

Se puede concluir que este tipo de iniciativas oficiales sirvieron parcialmente para encauzar la lucha por la tierra hacia canales burociáticos; pero en la práctica fueron más eficaces aquellas organizaciones surgidas de los mismos campesinos y que intentaron mantener su independencia respecto a las primeras. Así, los campesinos ejercieron durante estos años una presión real sobre el gobierno, cuyo resultado fue el reparto de tierras.

En 1927 Obregón obtuvo el apoyo del PNA para su candidatura, lo que permitió a los agraristas volver a ocupar un importante lugar poli-

17 Sergio Reyes Osorio, el al., Estructura agraria y desarrollo agrícola en México, México, Fondo de Cultura Económica, 1974, p. 599-600. 
tico del que habían sido desalojados durante la administración callista; a la muerte de Obregón en 1928, este partido exigió un cambio de línea a la elite política y por eso se promovió a Portes Gil para presidente. Sin embargo, el daño estaba consumado: las organizacionés campesinas se escindieron definitivamente del proletariado, condición que fue hábilmente manejada por los creadores del Partido Nacional Revolucionario creado en 1929.

El último nivel de organización que el gobierno callista se propuso era el del interior de las comunidades y ejidos. Recordemos que Calles, después de haber sido declarado presidente electo, inició una gira por Europa, donde conoció las cooperativas de crédito rural fundadas por Raiffeisen y Schultze-Delitch que le impresionaron por su eficaz funcionamiento y que a partir de entonces se convirtió en un convencido del cooperativismo. A su regreso ordenó una campaña de difusión de los beneficios del sistema como etapa preparatoria para su implantación. Posteriormente distribuyó gratuitamente el Manual para fundadores de Cooperativas en México.

Luego de preparar terreno, se trabajó en la formulación de la Ley General de Cooperativas, la cual, aprobada por el Congreso fue publicada el 10 de febrero de 1926; con ello se trató de implantar el sistema de cooperativas de producción y consumo entre los ejidatarios. Sin embargo, el resultado de la aplicación de la Ley fue pobre, ya que una vez más se trataba de imponer un sistema de organización de la producción y consumo ajeno a las formas tradicionales campesinas.

\section{REPARTO AGRARIO}

La legislación era considerada como el motor propulsor, de ahí el gran número de iniciativas legales del ejecutivo en materia agraria, mismas que si bien fueron modificadas o ampliadas, son la base de la legislación agraria actual.

El proyecto de la Ley Reglamentaria sobre Repartición de Tierras Ejidales y Constitución del Patrimonio Parcelario Ejidal fue elaborado por los técnicos de la Secretaría de Agricultura y Fomento, especificamente por Marte R. Gómez y Emilio Portes Gil. Fue aprobada y publicada el 19 de diciembre de 1925 y posteriormente se expidió su Reglamento el 5 de abril de 1926. De principio, la ley contravenía lo asentado por la circular 51 que establecía la tenencia y el trabajo colectivos del ejido.

En la exposición de motivos se señalaba que la falta de seguridad de los beneficiarios repercutía necesariamente en la baja productividad y en detrimento del arraigo a la tierra, situación por demás contraria a los planes oficiales de eficiencia en el campo. Por ello se hacía necesario legalizar la intervención del Estado en la organización de los ejidatarios, reduciendo el poder de sus autoridades - Comité Administrativo- cuyo trabajo se concretaria a dividir el ejido y a entregar una parcela a cada miembro, al tiempo que se le imponía un consejo de vigilancia que evitaría cualquier abuso.

La ley destacaba la introducción del concepto - aunque ambiguo-de la propiedad privada dentro de los ejidos, a la vez que pretendía que el arraigo de la misma trajera por consecuencia la aún no alcanzada estabilidad social. Esta ley incluía los siguientes aspectos: la ratificación de que la capacidad juridica de los pueblos para poseer en común tierras, bosques y aguas, radica en la masa de ejidatarios del pueblo. También se 
consideraba que el Comité Administrativo cesaria en sus funciones en cuanto se llevara a cabo el fraccionamiento de las tierras entre los beneficiarios, cuyo representante sería el Comisariado Ejidal, compuesto por un presidente, un secretario y un tesorero, cuyas funciones principales serian las de representar jurídicamente al pueblo así como promover el mayor aprovechamiento de los recursos recibidos. El Consejo de Vigilancia, constituido por tres personas, cuidaría que el Comisariado actuara de acuerdo con los intereses de los ejidatarios en su conjunto. La Comisión Nacional Agraria sería la responsable de elaborar y presentar el proyecto de fraccionamiento y adjudicación, que debía señalar la zona urbana, la de montes y pastos, un lote para la escuela rural y una zona de reserva para dotar de tierras a los hijos de los ejidatarios con edad suficiente o para otros ejidatarios provenientes de poblados aledaños donde no las hubiera disponibles. En cuanto a la ampliación se preveían dos formas: una a corto plazo, consistente en incrementar las zonas de cultivo mejorando las de menor calidad, y otra a largo plazo, cuya meta era la dotación de más tierras por medio de otra acción agraria, sólo después de diez años a partir de la fecha de la primera. Se estableció por primera vez que la propiedad ejidal sería inalienable e inembargable. Asimismo, se impuso al beneficiario la obligación de trabajar la tierra so pena de perderla si durante un año no la cultivaba sin causa justificada. Finalmente, se asentó que la parcelación del ejido. no fuera obligatoria; la decisión se tomaría por la asamblea general. En cuanto al disfrute y trabajo de bosques y aguas, continuó siendo comunal en todos los casos. ${ }^{18}$

De hecho, esta Ley es la ratificación de la forma de tenencia comunal colonial y precortesiana, pues los ejidatarios sólo tienen el usufructo que se trasmite de generación en generación. A pesar de que con esta ley se propuso fomentar la llamada "vía farmer" de desarrollo, sólo se estableció una tendencia al minifundio, pues no señalaba la extensión ni la calidad de la parcela, por lo que se determinó la necesidad de modificarla posteriormente.

Otra iniciativa legal relevante en materia de reparto agrario fue la Ley de Dotaciones y Restituciones de Tierras y Aguas, del 23 de abril de 1927, reglamentaria del artículo 27 constitucional, cuyo autor, Narciso Bassols, le dio su nombre.

El principal motivo de la formulación de esta Ley, que representó el primer intento formal de codificación agraria fue tratar de organizar el procedimiento agrario acorde con una técnica jurídica que lo hiciera "inatacable constitucionalmente". Esta disposición abarcaba los aspectos nodales de la reforma agraria y ponía fin a la anarquía de la legislación anterior. A pesar de que la Ley de Dotaciones y Restituciones de Tierras y Aguas constituyó la cima legislativa de este periodo al incorporar las experiencias normativas anteriores y haberlas organizado lógicamente y depurado, no cesó con ello el esfuerzo legislativo, haciendo además posteriores modificaciones.

La citada ley señalaba que todo poblado con más de 25 individuos capacitados para recibir tierras y que careciera de tierras o aguas, o si las que tuviere no le fueran suficientes, tenía derecho a ser dotado de ellas. El sujeto legal era el poblado, no el individuo. Se indicaba también que lo único en común del ejido colonial con el nuevo concepto de ejido

18 Lucio Mendieta y Núñez, El problema agrario en México, México, Editorial Porrúa, 1978, p. 233-236. 
posrevolucionario era el nombre, pues el anterior llevaba implícito el carácter comunal.

En otro renglón, esta ley planteaba un nuevo tipo de juicio ante tribunales especiales que no cuestionaran la constitucionalidad del mismo, y cambiaba la tónica anterior de cuando, realizándose ante autoridades civiles, provocaba retrasos en su proceso e inseguridad de ambas partes.

De esta manera quedó claro que lo reclamable por el afectado sería la indemnización correspondiente, y que no podría tener injerencia en el proceso expropiatorio, ya que éste se basaba en el interés público, quedando improcedente el amparo en materia agraria.

Este nuevo ordenamiento destacó la tendencia a centralizar el control en la Comisión Nacional Agraria, al establecer que las dotaciones provisionales primero tendrian que ser aprobadas. Se consideraba que la pequeña propiedad debía tener una superficie 50 veces mayor que la extensión de la parcela individual; a ésta se le otorgaba una superficie de riego de dos a tres ha y de nueve en tierras de temporal de tercera. Sin embargo, ante la falta de tierras se previó que lo mínimo intocable de la pequeña propiedad sería 50 ha de cualquier calidad. También se determinaba la validez de los fraccionamientos y la venta de tierras afectables y sus gravámenes, asi como de las obras y cultivos que se exceptuaban de afectación.

Del análisis de la ley se desprenden las siguientes observaciones:

a) La nueva norma fue hecha pensando más en el reparto de tierras que en la capacidad del ejido como unidad económica, susceptible de participar productivamente en la vida nacional;

b) Aunque define la inalienabilidad de la parcela y se concede su tutela al ejidatario, también mira con benevolencia al terrateniente; por ello actúa con cautela, temiendo destruir la economía agrícola si no se cuenta con otro recurso que la supla;

c) La necesaria aprobación de las dotaciones provisionales por la Comisión Nacional Agraria permitió que numerosos terratenientes recurrieran a la Suprema Corte de Justicia para ampararse contra las afectaciones. Por otra parte, esta situación originó que en lo sucesivo se enfrentaran terratenientes y pequeños propietarios al Estado y no a las autoridades locales. En muchos de estos casos, la parte civil ni siquiera se defendía, siendo objeto de despojo de tierras y aguas por la decisión del juez de distrito. En gran número de juicios, los fallos fueron favorables a los terratenientes y los campesinos se vieron obligados a devolver las tierras; pero en cuanto a la pequeña propiedad, continuó siendo afectada, lo cual creaba gran tensión en el campo;

d) Se concedió legalmente un mayor peso a las dotaciones que a las restituciones, pues este segundo procedimiento era mucho más complicado, además de que generalmente las tierras reclamadas para su restitución eran de mejor calidad, por lo que sus propietarios buscaban todas las posibilidades para retenerlas;

e) La reducción de la superficie de la parcela de cinco a dos y tres ha resultó insuficiente (como se ve en el cuadro siguiente) para proporcionar trabajo de tiempo completo al ejidatario. 


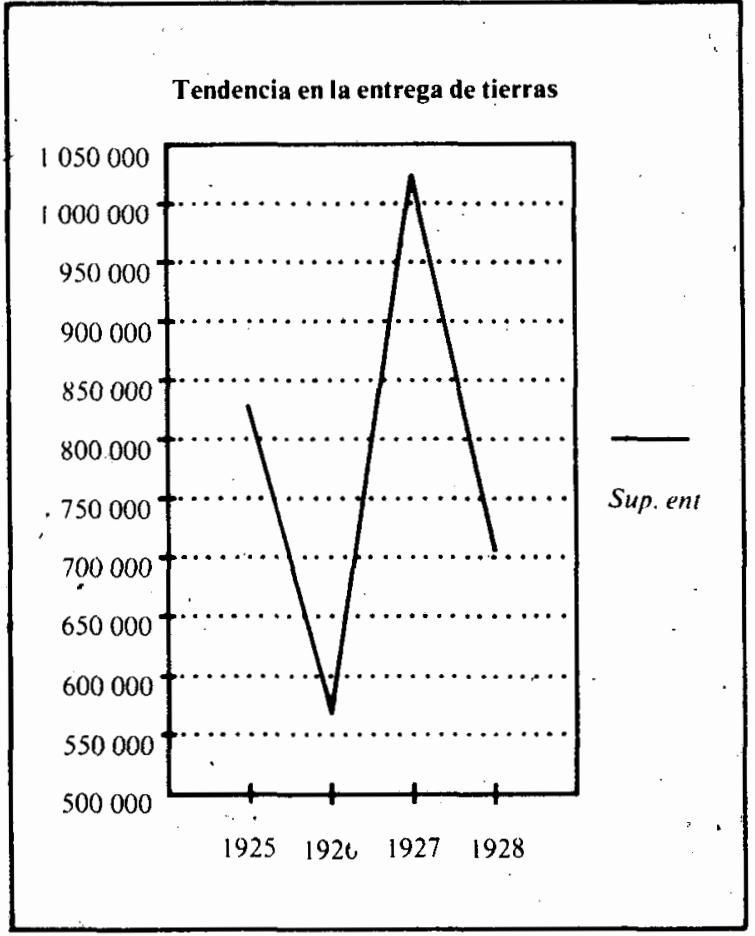

!. El gobierno callista emprendió en estos años un amplio programa de legislación que reestructuraba el derecho agrario, por lo que se retuvieron numerosos expedientes en trámite, tales como el parcelamiento ejidal, para ajustarlos a las nuevas disposiciones.

2. Los esfuerzos se dirigieron principalmente a otros aspectos del programa agrario, como financiamiento, infraestructura, colonización, educación, etc., de manera que el reparto fuera efectivo.

3. La administración callista se vio obligada a canalizar gran cantidad de recursos al control militar, por el inicio de la rebelión cristera.

El año 1927 presenta un notable incremento en la curva del reparto alcanzando casi el $100 \%$ más que el año anterior. Las razones pueden ser las siguientes:

1. Se resolvieron numerosos expedientes que se encontraban en trámite. Con ello el gobierno trató de obtener el apoyo de los campesinos beneficiados y de esa manera frenar la expansión del movimiento cristero.

2. La politica agraria se orientó definitivamente al reparto, más que a los otros factores de la reforma agraria integral, por la imposibilidad objetiva de continuar la empresa, principalmente por falta de récursos económicos (como el incremento de la deuda agraria) y por problemas de orden político.

Hacia 1928 se percibe nuevamente una disminución en el reparto de tierras que puede explicarse por: 
1. La efectiva presión que ejercieron los Estados Unidos por medio de su embajador Dwigth Morrow, para poner un alto al crecimiento de la deuda agraria producto de las expropiaciones; de esta manera el gobierno mexicano podría cubrir mejor sus obligaciones con las deudas externas e internas.

2. La aplicación de la Ley Bassols que complicaba y retardaba el procedimiento. Por otra parte, la instauración del juicio agrario fue otro elemento de oposición de los propietarios susceptibles de afectación por reparto de tierras.

3. La baja en la producción nacional agricola y la necesidad de importar granos, cada vez en mayores volúmenes, puso en tela de juicio la capacidad del ejido como medida alternativa desde el punto de vista de la producción.

4. Se hizo patente el fracaso de la iniciativa de la reforma agraria integral y se inició un periodo de desilusión de los técnicos del gobierno en cuanto a resolver el problema del campo en ese sentido.

5. El proceso político - la reelección de Obregón - adquirió la mayor importancia en el plano nacional y gran cantidad de recursos se desviaron hacia este concepto.

6. El proceso de institucionalización de la reforma agraria orientó por canales burocráticos la demanda de tierras.

En lo que se refiere a la calidad de la tierra, de la superficie total entregada (3.179 903 ha), la mayor parte, el $78 \%$, correspondía a tierras indefinidas, o sea tierras poco o nada utilizables por el momento.

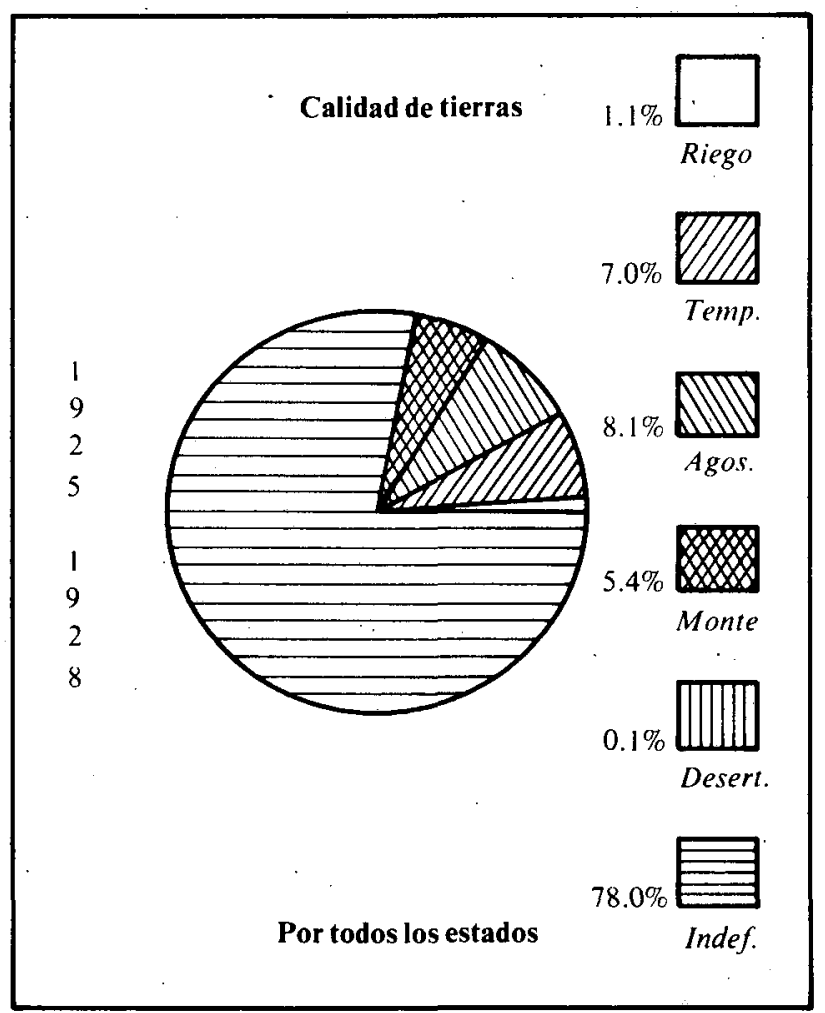


Las tierras indefinidas necesariamente deben entrar en cualquiera de los otros tipos de tierras; sin embargo, en esta época se las llabama así debido al desconocimiento del terreno. Eran tierras que generalmente no estaban abiertas al cultivo y eran inaccesibles por falta de infraestructura y de técnica agronómica. Ello constituye un indicador de que lo establecido por la ley de 1927 sólo se cumplió parcialmente, pues aunque la parcela superó la superficie por beneficiario (11.3 ha), no fue asi en cuanto al área minima de riego y temporal, que fue de sólo 0.80 ha en promedio.

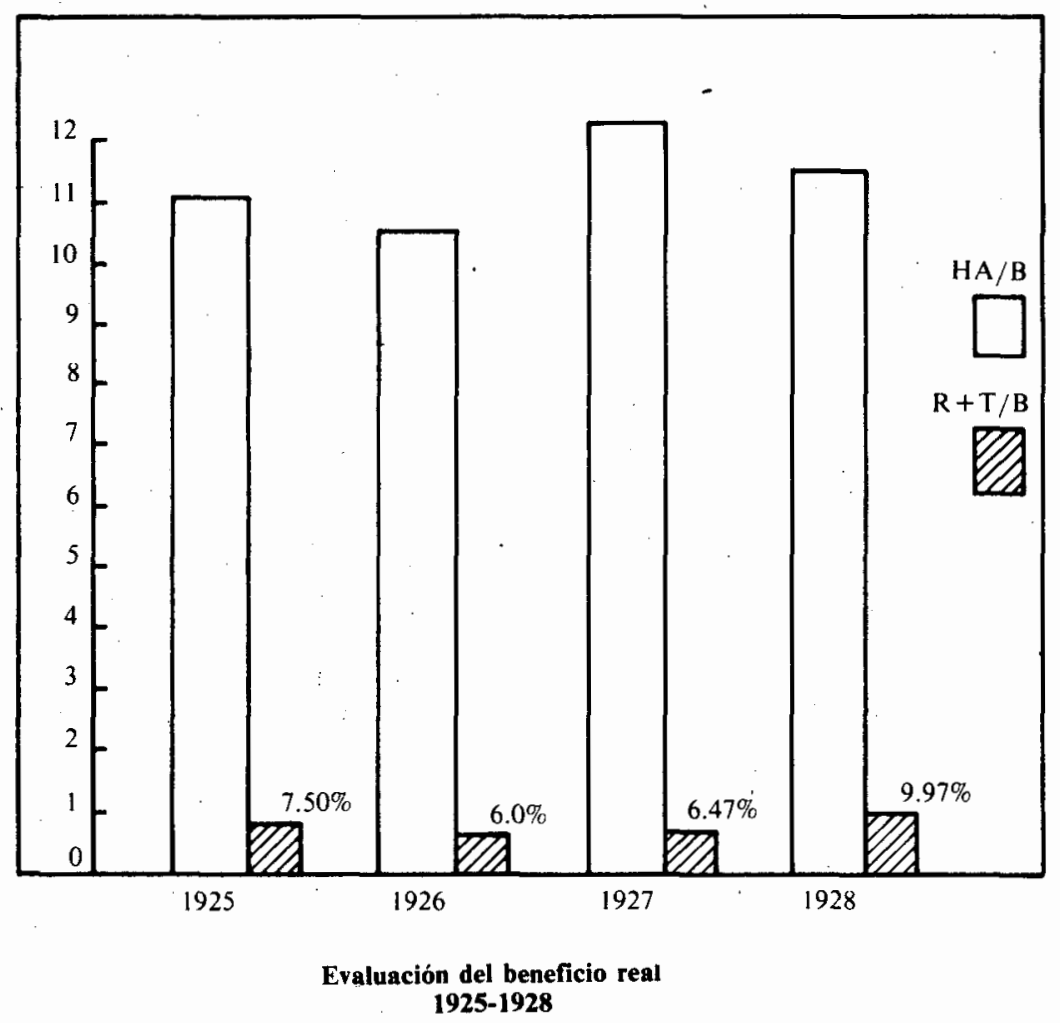

En la práctica, la redistribución de la tierra se inclinó principalmente a la dotación, pues implicaba beneficiar a un mayor número de solici-' tantes, aunque significara una superficie menor para cada uno de ellos. La medida respondió seguramente a que las restituciones conllevan una tramitación más complicada y larga, pero fundamentalmente a que los núcleos solicitantes, en la mayoría pequeños, reclamaban el área que originalmente les pertenecía y que debían ser esas tierras y no otras las que se les restituyeran. Esto naturalmente siempre implicaba la desposesión de quiénes detentaban la tenencia e inevitablemente producía tensión social.

Por otro lado, la limitante impuesta por el artículo 27 , de que toda solicitud de restitución debía referirse a despojos realizados antes del 5 de febrero de 1917, impedía el reclamo de los que hubiesen sido despojados después de esa fecha; no obstante, sin lugar a duda, este problema continuó suscitándose. 
Superficie entregada entre 1925-1928
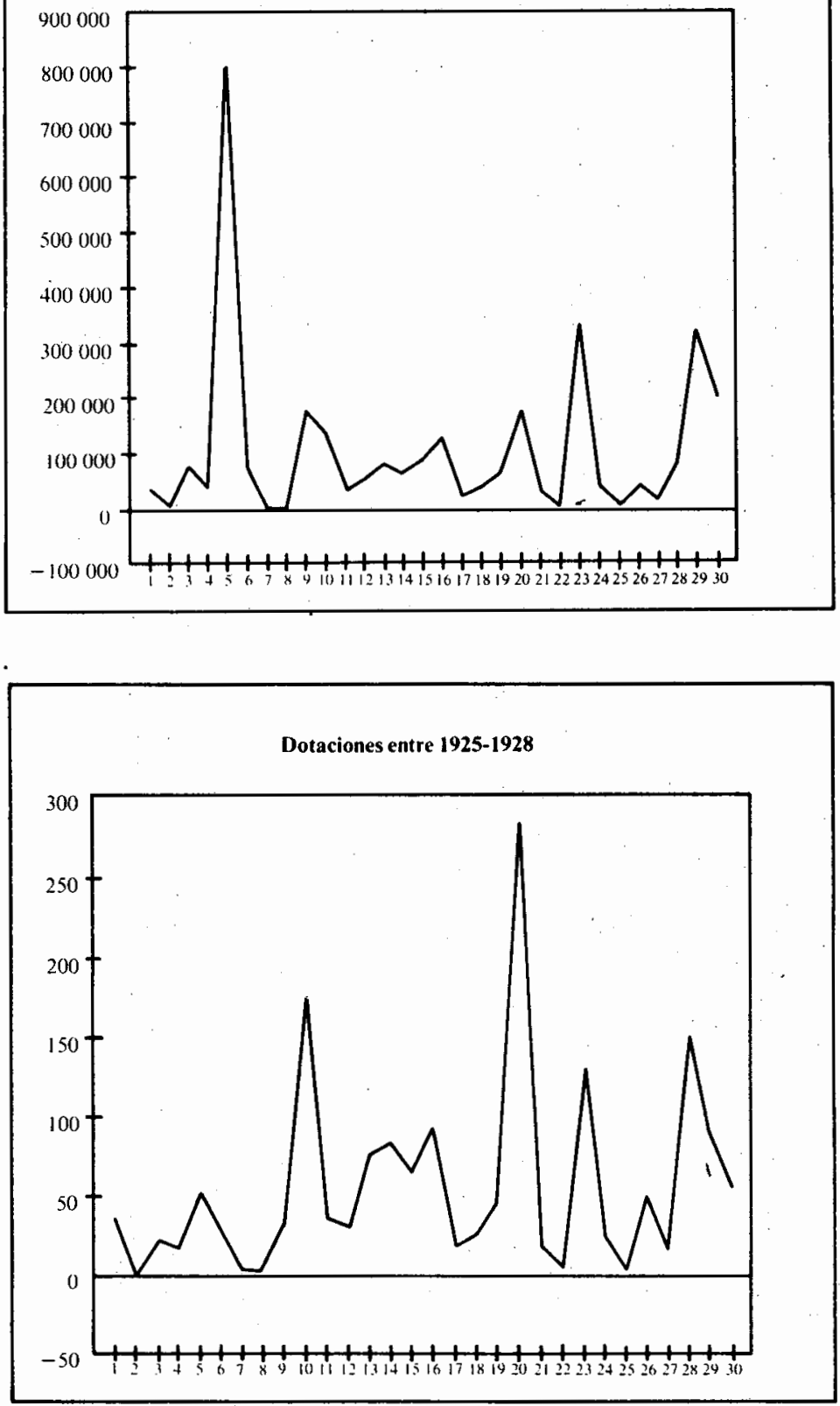

1. Aguascialientes

2. Baja California Sur

3. Campeche

4. Chialpits

5. Chihuahui

6. Coahuilia

7. Colima

8. Distrito Federal
9. Durango

10. Estado de México

11. Guanajuato

12. Guerrero

13. Hidalgo

14. Jalisco

15. Michoalcán

16. Murelos
17. Nayarit

18. Nuevo León

19. Oaxacid

20. Puebla

21. Querétaro

22. San Luis Polosi

23. Sinalod

24 . Sonora
25. Tabasco

26. Tamaulipas

27. Tlaxcalia

28. Veracruz

29. Yucitán

30. Zacatecas 
A pesar de los obstáculos mencionados, la dotación alcanzó el 94.67\% del total de las acciones agrarias, beneficiando al $96.54 \%$ de los solicitantes, correspondiéndoles el $76.50 \%$ de la tierra entregada. Sin embargo, si bien este tipo de acción tuvo la mayor y mejor superficie, ést a tuvo que dividirse entre el más alto número de beneficiarios, por lo que correspondió, en relación con las otras acciones, sólo el $7.71 \%$ de área a cada uno, con un beneficio real del $46 \%$. A diferencia de lo que sucedió en las restituciones (donde el más beneficiado fue el norte), la región que rècibió mayor cantidad de dotaciones fue la conformada por Puebla, México, Veracruz y Morelos, donde se concentró el $60.40 \%$ de los receptores, mientras que el norte constituyó solamente el 24.52 y el sur el 15:07. Cabe señalar también que las tierras para dotaciones constituyeron la mayor parte de las afectaciones de las áreas más productivas; sin embargo, la dotación absorbió además el $100 \%$ de tierras tomadas de terrenos nacionales, en su mayor parte de calidad indefinida; es decir, poco o nada productivas en ese momento.

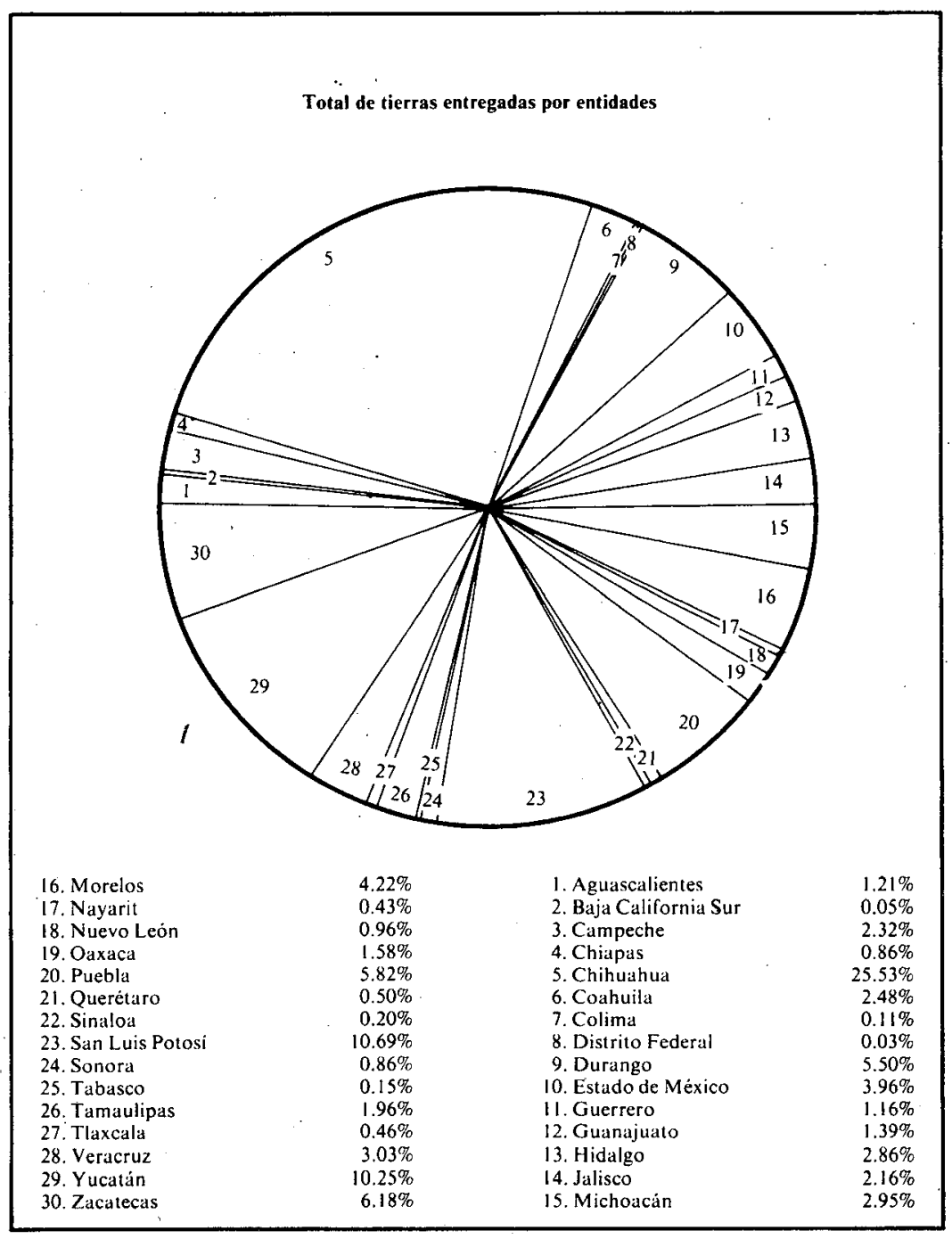


La gráfica del total de tierras entregadas por entidades nos muestra que las más favorecidas por la acción agraria fueron Chihuahua, San Luis Potosí y Yucàtán, debiéndose seguramente a la mayor disponibilidad de tierra y a su calidad - generalmente "indefinida" o de agostadero-, y a la correlación de fuerzas de los demandantes de tierras.

Estas breves consideraciones nos llevan a la conclusión que, en el aspecto redistributivo de la tierra, la reforma agraria, tal como se la planteó Calles, no podía llevarse a cabo; cabe señalar que en ello influyeron también las presiones políticas, tanto externas (como las que ejercieron los Estados Unidos), como las internas (las rebeliones de Serrano y Gómez y el movimiento cristero).

En la práctica, el programa agrario 1924-1928 se enfrentó a una realidad mucho más compleja que la concebida por Calles; es decir, que el programa ideado a partir del interés y conocimiento de un grupo no pudo realizarse, pues no correspondía a las condiciones objetivas ni a las expectativas de la gran mayoría rural. De ahí que el presidente terminara actuando más como político, repartiendo tierras donde las hubiera, que como técnico, proveyendo de todos los recursos necesarios de acuerdo con su plan.

Sin embargo, en el periodo gubernamental mencionado se establecieron las bases del desempeño de la reforma agraria en un marco institucional; de esta manera, el programa de reforma agraria integral aparece como un antecedente inmediato de aquéllos que los regímenes posteriores han elaborado sexenio tras sexenio.

Al revisar las carencias, fracasos y logros de la administración callista en la materia, se clarifican, en alguna medida, las razones por las cuales este viejo problema es tan actual. 